\title{
OS FATORES QUE INFLUENCIAM O SERVIÇO AEROMÉDICO NA URGÊNCIA E EMERGÊNCIA NOS DIAS ATUAIS
}

Alberto César da Silva LOPES ${ }^{1}$; Reila Campos Guimarães de ARAÚJO²; Valnizete Trindade de MOURA ${ }^{3}$; Victor Augusto de CASTRO ${ }^{4}$

\section{RESUMO}

Justificativa: Há evidências científicas que o quanto antes um paciente em situação crítica for atendido menor são os riscos de lesões e sequelas permanentes, e o tempo é um fator fundamental para a diminuição desses riscos reforçando a importância do serviço aeromédico nos dias atuais. Objetivo: Demonstrar através da pesquisa os fatores que influenciam o serviço aeromédico na urgência e emergência nos dias atuais. Métodos: Trata-se de uma revisão bibliográfica de artigos científicos publicados preferencialmente nos últimos cinco anos, na base de dados da Biblioteca Virtual em Saúde (BVS), no período de julho e agosto de 2019. Resultados: Os achados trazem contribuições relevantes para que se busquem mais aprimoramento nessa área e nessa perspectiva contribuir com os estudos e pesquisas cientificas demonstrando sua importância para o serviço. Conclusões: Este estudo permitiu compreender a relevância do entendimento técnico e cientifico quanto ao serviço aeromédico e seus diferentes fatores influenciadores.

Palavras-chave: Resgate aéreo, Emergência, Aeroespacial.

\section{INTRODUÇÃO}

Serviço aeromédico consiste no resgate ou na remoção de doentes graves, por meio de helicópteros ou aeronaves.

O Brasil é geograficamente extenso, sendo necessário a disponibilidade de um serviço de urgência e emergência para atender as áreas distantes remotas e de difícil acesso, ofertando um serviço rápido e eficiente possibilitando um bom prognóstico da vítima (DIAS \& PENNA, 2014).

De acordo com o Ministério da Saúde é o serviço realizado por aeronaves de asa fixa ou rotativa, onde no APH (Atendimento pré-hospitalar) há uma definição para todos os veículos de atendimento, as aeronaves são

\footnotetext{
${ }^{1}$ Enfermeiro, especialista em Enfermagem em Urgência e Emergência; Terapia Intensiva adulto; Cardiologia; Saúde Pública e Saúde da Família. E-mail: professor.albertocesar@gmail.com

Enfermeira, doutoranda em Ciências da Saúde da Universidade Federal de Goiás, Jataí-GO. E-mail: reilacampos@ufg.br

${ }_{4}^{3}$ Enfermeira, especialista em Enfermagem em Urgência e Emergência. E-mail: valnizete@hotmail.com

Enfermeiro, especialista em Oncologia Clínica e Auditoria dos Serviços de Saúde. E-mail: victoraugusto91@hotmail.com.
} 
classificadas como sendo do tipo "E", sendo que as de asa rotativa são utilizadas para resgates e asa fixa para transportes inter-hospitalar.

Um dos fatores mais importantes do acionamento deste serviço se dá pela eficácia do atendimento às vítimas que necessitam de atendimento de suporte avançado que estejam impossibilitados de receber assistência por ambulância terrestre devido a gravidade e ou distância do serviço hospitalar, sendo transportada para o hospital de referência mais próximo do local da ocorrência (NARDOTO e colaboradores, 2011).

Nesse contexto, a busca pela qualidade de assistência dos serviços de transporte aeromédico em virtude do aumento da frequência de remoção aérea de pacientes em estado crítico (BONIN e colaboradores, 2016), suscita que o tempo é comparado ao ouro no atendimento de emergência e o tempo do atendimento pré-hospitalar até o atendimento definitivo no hospital deve ser o menor possível, preferencialmente, em menos de uma hora. Nessa perspectiva, o presente estudo teve como objetivo demonstrar os fatores que influenciam o serviço aeromédico na urgência e emergência nos dias atuais.

\section{METODOLOGIA}

Trata-se de uma pesquisa bibliográfica, de natureza qualitativa com busca de publicações sobre o tema realizada na Biblioteca Virtual em Saúde (BVS), Centro Latino-Americano e do Caribe de Informação em Ciências da Saúde e na Scientific Electronic Library Online (SCIELO). A busca pelos artigos foi realizada entre julho e agosto de 2019 e objetivou encontrar publicações de artigos científicos relacionados aos descritores: Resgate aéreo, Emergência, Aeroespacial. Leituras adicionais das referências citadas no artigo também foram realizadas.

Como resultado da pesquisa inicial Resgate aéreo, Emergência e Aeroespacial (relativo ao que está no ar) emergiram 15 relatos de pesquisa, para refinamento da busca foram usados critérios de inclusão e exclusão (tabela 1). 
Tabela 1 - Critério de inclusão e exclusão dos artigos para revisão.

Inclusão

Exclusão

\begin{tabular}{c|c}
\hline $\begin{array}{c}\text { Artigos publicados preferencialmente } \\
\text { entre os anos de } 2014 \text { a } 2018\end{array}$ & $\begin{array}{c}\text { Alguns artigos anteriores ao ano de } \\
2014 \text { ou posterior a } 2018\end{array}$ \\
\hline $\begin{array}{c}\text { Conter no título ou nos resumos os } \\
\text { termos: Resgate aéreo, Emergência, } \\
\text { Aeroespacial }\end{array}$ & $\begin{array}{c}\text { Estudos em outros idiomas que não } \\
\text { português, inglês e espanhol }\end{array}$ \\
\hline $\begin{array}{c}\text { Artigos de boa qualidade metodológica } \\
\text { publicados em periódicos }\end{array}$ & $\begin{array}{c}\text { Outros materiais que não fossem } \\
\text { artigos; Artigos não disponíveis na } \\
\text { íntegra online }\end{array}$ \\
\hline
\end{tabular}

Fonte: Organização dos autores

\section{RESULTADOS E DISCUSSÕES}

Após aplicar os critérios de elegibilidade emergiram 15 artigos os quais foram lidos na íntegra e 8 excluídos pois não atingiam a temática abordada nesta pesquisa, sendo assim abordaremos neste trabalho 7 artigos.

Ao analisar as características gerais dos artigos, observou-se que um artigo aponta a preocupação quanto à segurança para os tripulantes e riscos para os pacientes durante o transporte, pois, longas distâncias de voo podem ser associadas à intercorrências com o paciente (BONUZZI e colaboradores, 2016). Já SCHWEITZER e colaboradores (2016) sinalizaram que o Suporte Avançado de Vida é realizado exclusivamente por enfermeiros e médicos por ter como características manobras invasivas, sendo assim os membros da equipe devem estar sempre qualificados e treinados para atendimentos nesse seguimento.

Como é de grande importância o trabalho em conjunto e sincronia, Dias e colaboradores (2017) refere que os profissionais atuantes nesta área que trabalham em equipe assumem posição de destaque. Neste sentido, Bonin e colaboradores (2016) afirmam que estratégias educativas auxiliam esse processo.

Nardoto e colaboradores (2011) enfatiza que no Brasil utiliza-se com maior frequência para resgate aéreo o helicóptero. Já DIAS \& PENNA (2014) afirmam que os primeiros profissionais da saúde que atuaram neste serviço 
tiveram dificuldades devido a falta de conhecimento por ser um ambiente diferente do habitual.

Conforme relata o MINISTÉRIO DA SAÚDE (2002) para atuação no serviço aéreo deve-se respeitar as prerrogativas legais de segurança de voo, obedecendo aos padrões de capacitação e atuação previstos no regulamento e normas vigentes.

\section{CONSIDERAÇÕES FINAIS}

O presente estudo evidenciou que o transporte aéreo sofre influência do conhecimento da tripulação, da distância dos voos e da preparação (estabilização hemodinâmica) prévia do paciente antes do transporte.

Conclui se ainda que estudos acerca dos fatores que influênciam no serviço aeromédico devem ter mais destaque no meio científico para enfatizar e demonstrar a sua importância, portanto sugere-se estudos futuros com maior abrangência e qualidade metodológica.

Esta pesquisa não recebeu financiamento específico de nenhuma agência de fomento dos setores público, comercial ou sem fins lucrativos.

\section{REFERÊNCIAS}

1. BONUZZI kl, Muniz Silva CCS, Santos OP, Moraes Filho IM. Atuação do Enfermeiro no Atendimento Pré hospitalar aéreo a Pacientes Politraumatizados. Revisão de literatura. Rev. Cient. Sena Aires. 2016; 5(2):

171-77.

2. BONIN WLM, Abrahão AL et al. Estratégia de Educação Permanente para o Apoio Aeromédico. Revista de Enfermagem UFPE On Line, Recife, 2016.

3. DIAS \& PENNA. Transporte Aéreo: O Cotidiano dos Profissionais da Saúde. Revista de Enfermagem UFPE On Line, Recife, 2014.

4. DIAS CP, Ferreira FL, Carvalho VP de. A Importância do Trabalho em Equipe no Transporte Aéreo de Pacientes. Revista de Enfermagem UFPE On Line, Recife, 2017.

5. MINISTÉRIO DA SAÚDE. Política Nacional de Atenção às Urgências. portaria n. ${ }^{2}$ 2048/gm, em 5 de novembro de 2002. Série E. Legislação de Saúde. 
6. NARDOTO, Emanuella Maria Lopes; DINIZ, Jackeline Maria Tavares; CUNHA, Carlos Eduardo Gouvêa da. Perfil da vítima atendida pelo serviço préhospitalar aéreo de Pernambuco. Rev. esc. enferm. USP, v.45, n.1, p. 237242, 2011.

7. Schweitzer G, Nascimento ERP, Nascimento KC, Moreira AR, Amante LN, Malfussi LBH. Emergency interventions for air medical services trauma victims. Rev Bras Enferm [Internet]. 2017;70(1):48-54. DOI: http://dx.doi.org/10.1590/0034-7167-2016-0311. 